\title{
Freeze Dried Blueberry Powder Fortification Improves the Quality of Gluten Free Snacks
}

Sikha Bhaduri* and Khursheed P Navder

School of Urban Public Health at Hunter College, CUNY School of Public Health, NY, NY 10035

\begin{abstract}
Since Quinoa flour is an excellent source of natural antioxidant compounds and blueberries are rich in polyphenolic anthocyanins, this study was undertaken to improve and evaluate the quality of two blueberry powder fortified gluten free products, muffins and cookies. Control products were made with $100 \%$ Rice flour and Rice flour was replaced by $50 \%$ and $100 \%$ Quinoa flour to prepare muffin and cookies. $10 \%$ freeze dried Blueberry powder was used for fortification. Effect of flour replacements and Blueberry fortification on moisture content, water activity, antioxidant value, shelf life, sensory quality and textural properties were studied. Blueberry fortification improved the shelf life of the baked products, since, no significant increase in water activity and moisture content and no microbial growth were observed during 3 months of storage. Fortified Quinoa muffins and cookies were significantly harder because of the high fiber content of the Quinoa flour found by a Textural profile analysis using TA.XT plus Texture Analyzer. Although, baking reduced the antioxidant content to some extent, the total antioxidant activity, phenolic content and anthocyanin content were significantly increased with Blueberry fortification. Freeze dried blueberry powder fortified $100 \%$ Rice flour muffins and 100\% Quinoa flour cookies were considered as the most acceptable products by consumer Sensory analysis using a 9-point hedonic scale. The study suggests that Quinoa flour is a good gluten free alternative and Blueberry fortification to snack products is a simple way to increase phytochemical and antioxidant content in diet.
\end{abstract}

Keywords: Quinoa flour; Blueberry fortification; Antioxidant activity; Sensory evaluation; Texture profile analysis

\section{Introduction}

Natural compounds have long been used for the development of modern therapeutic drugs. There is a recent increase in the search for new phytochemicals from edible medicinal plants since their antiinflammatory and anti-allergenic agents tend to reduce the risk of many diseases. Foods containing antioxidants are associated with reduced risk of chronic health disorders, including Cancer and Cardiovascular disease. Celiac Disease (CD), a gluten sensitive inflammatory disorder of the small intestine, also known as gluten intolerance, is a diet related autoimmune enteropathy characterized by chronic inflammation of intestinal villi and mucosa due to gluten intolerance. The only effective treatment [1] for CD is a life-long gluten-free diet. Gluten-free breads and cookies are typically made from rice or maize flours with low content and poor-quality proteins. Therefore, preparation of glutenfree bakery food product from high quality gluten free grains has become a growing challenge for food technologists and nutritionists.

Quinoa (Chenopodium quinoa Wild) has gained increasing interest in recent years due to its high nutritive value. It is a pseudo cereal grown mainly in the Andes and has become a popular gluten free flour because of its high nutritional value [2]. The World Health Organization has rated Quinoa to be a super grain and considers it to be equivalent to milk since it contains high levels of potassium, riboflavin, B6, niacin and thiamin along with magnesium, zinc, copper, manganese and some folate. The calcium, iron, phosphorus, magnesium and zinc contents are particularly higher in Quinoa compared to wheat, corn, rice, barley, oats, rye and triticale [3]. Quinoa is an excellent (6\% of the total weight) source of easily digestible dietary fiber, and is rich in protein (13.81\%), compared to other cereals. It is also a good source of vitamin E [4] and also it is an important source of antioxidants [5].

Fruits and vegetables are not only rich sources of vitamins, minerals, and fiber; they are also rich in bioactive compounds known as phytochemicals [6]. Much of the disease prevention potentials of fruits and vegetables in human health attributed to these phytochemicals $[7,8]$ are through their antioxidant properties. Although, the benefits of individual phytochemical supplements are largely unproven, laboratory studies have shown them to suppress tumor growth, interfere with sexual hormones, prevent blood clots, and have antiinflammatory properties. Polyphenols are important phytochemicals and are probably the most investigated molecules of nutritional interest [6]. Polyphenols are found in celery, cranberries, onions, kale, dark chocolate, broccoli, apples, cherries, berries, tea, red wine or purple grape juice, parsley, soybeans, tomatoes, eggplant, and thyme. Most common berries contain polyphenolic compounds and are particularly rich in potent antioxidants. Phenolic antioxidants are believed to possess antioxidative, anti-inflammatory antimicrobial properties $[9,10]$ and are associated with reduced lung cancer, cardiovascular disease and chronic obstructive pulmonary diseases [11-13].

Considering the benefits of Quinoa flour and dry blueberry powder, this study was undertaken to study gluten free snacks made from Quinoa flour fortified with freeze dried blueberry powder. Two popular snacks, muffins and cookies were prepared and both were fortified with $10 \%$ freeze dried Blueberry powder. It was of interest to study the effect of flour replacements and fortification on moisture content, water activity, antioxidant value, shelf life, sensory quality and textural properties.

*Corresonding author: Sikha Bhaduri, School of Urban Public Health at Hunte College, CUNY School of Public Health, NY, NY 10035, Tel: +1 212396 7789; E-mail: sbhaduri@hunter.cuny.edu

Received October 09, 2014; Accepted November 03, 2014; Published November 12, 2014

Citation: Bhaduri S, Navder KP (2014) Freeze Dried Blueberry Powder Fortification Improves the Quality of Gluten Free Snacks. J Food Process Technol 5: 396. doi:10.4172/2157-7110.1000396

Copyright: @ 2014 Bhaduri S, et al. This is an open-access article distributed under the terms of the Creative Commons Attribution License, which permits unrestricted use, distribution, and reproduction in any medium, provided the original author and source are credited. 


\section{Materials}

Modified Muffin [14] and Cookie [15] recipes were made with Rice and/or Quinoa flour (Bob's Red mill, Milwaukie, OR), granulated white sugar (Domino Foods, Inc., Yonkers, NY, USA), salt (IGA brand, IGA Inc., Chicago, IL, USA), double-acting baking powder (Clabber Girl, Co., Terre Haute, IN, USA), canola oil (Safeway brand, Safeway Inc., Pleasanton, CA, USA), 2\% reduced fat milk (Safeway brand, Safeway Inc.), fresh large eggs, nonfat dry milk and unsalted butter as shown in Table $1 \mathrm{a}$ and $1 \mathrm{~b}$. Freeze-dried blueberry powder was purchased from Z Natural Foods (West Palm Beach, FL 33411 USA). Since fresh blueberry contains approximately $80-90 \%$ moisture and flour and fresh blueberries ratio in baked food products is usually 1:1 (www. blueberrycouncil.org/blueberry-recipes), $10 \%$ freeze dried blueberry powder was used in this study.

DPPH (2, 2- diphenyl-1-picrylhydrazyl), Trolox (6-hydroxy-2, 5, 7, 8 tetramethylchroman-2-carboxylic acid) and gallic acid were purchased from Sigma-Aldrich (St. Louis, MO). All other chemicals and solvents were of the highest commercial grade and were used without further purification.

\section{Baking procedures}

Muffin and cookie control recipes were made with Rice flour and the variations replaced the rice flour with $50 \%$ and $100 \%$ quinoa flour. For muffins, flour, sucrose, baking powder, and salt were mixed together in a separate bowl, and then were sifted into with the wet ingredients at speed 4 for 10 seconds. Muffin pans were filled with the batter (55-65g each) and were baked for 20 minutes or until done at $204^{\circ} \mathrm{C}$ in a preheated oven. For cookies, the ingredients were mixed to form a dough, which was rolled on a cookie sheet and cut with a cookie cutter. Cookies were baked at $218^{\circ} \mathrm{C}$ for $12-15$ minutes until they reach a pleasing golden brown color. Following five-minutes setting period, muffins and cookies were removed from the pans and allowed to cool on wire racks for one hour after which analyses were performed.

\section{Methods}

Moisture determination: Changes in moisture content and water activity due to substitution of Rice flour with Quinoa with or without fortification with blueberry powder were measured at different time intervals starting from 0 days to 3 months. Moisture was determined by moisture analyzer (OHAUS Explorer, MB 45, Pinebrook, NJ). Water activity was determined by a water activity meter (Decagon, CX-1). Muffins and cookies were sealed in an air-tight Zip-lock bag and stored at a regular refrigeration temperature. Moisture content and water activity were determined for four time periods from 0 days to three months for all the products. All measurements were made in triplicate.

Microbiological analysis: Observations were made for microbial growth for all stored products. To determine the microbial count of the samples Aerobic Plate Count was performed on Plate Count Agar (Sigma-Aldrich). The samples were diluted in the Phosphate Buffered Saline (PBS) by adding one gram sample in $9 \mathrm{~mL}$ of sterile phosphate buffered saline. The samples were serially diluted in the phosphate buffered saline. One $\mathrm{mL}$ from the dilutions was plated on Aerobic Plate Count Agar by spread plate technique. The plates were incubated at $30-32^{\circ} \mathrm{C}$ for $24-72$ hours. The colony count was performed with conventional plate count method [16]. All experiments were carried out in triplicates.

Preparation of extracts for antioxidant assays: Two solvent systems were used for extraction. Methanol was used for the antioxidant capacity assay and methanol/ $\mathrm{HCl}$ was used for the phenolic and anthocyanin content determinations, for extraction. 1 gram of freeze dried blueberry powder or 4 grams of batter for muffin and cookies were extracted with $20 \mathrm{~mL}$ of either methanol or methanol/ $\mathrm{HCl}(99: 1 \mathrm{v} / \mathrm{v}$ ) into a $50 \mathrm{~mL}$ polyethylene centrifuge tube for phenolic, anthocyanin and antioxidant capacity assays. The mixture was kept on a rotary shaker at $190-220 \mathrm{rpm}$ for 24 hours at room temperature. After 24 hours, the filtrate was centrifuged at $5000 \mathrm{~g}$ for 10 minutes, the supernatant was collected. The extraction was done at least three times with the residue and all three collected supernatants were pulled out together and were filtered through Whatman No. 4 filter paper and were stored at $4^{\circ} \mathrm{C}$ in airtight bottles for analysis in the next step. Extracts were analyzed in triplicate.

Determination of antioxidant capacity: A modified DPPH free radical quenching method [17] was used to determine the antioxidant capacity of methanol extracts. In this method Trolox was used as the reference standard and Results were expressed in terms of Troloxequivalent Antioxidant Capacity (TEAC), i.e., $\mu$ molTrolox/g dry mass (DM).The methanol extract as sample and Trolox solution as standard were reacted with 2,2- diphenyl-1-picrylhydrazyl (DPPH) solution and the absorbance changes were measured at $517 \mathrm{~nm}$. Briefly, $100 \mu \mathrm{L}$ of methanol extracts were put into the sample wells for samples and $100 \mu \mathrm{L}$ of methanol were added to control well in a 96-well microplates. Then $100 \mu \mathrm{L}$ of $0.208 \mathrm{mmol} \mathrm{DPPH}$ was added to all wells. $200 \mu \mathrm{L}$ of methanol was added to blank wells. The decrease in absorbance was determined every minute for $2 \mathrm{~h}$ or until the absorbance became steady in a microplate spectrophotometer (BioRad Laboratories, Inc., 2000 Alfred Nobel Drive, CA 94547,USA). Trolox solution was prepared in $50 \%$ methanol at concentrations of 10 , $20,40,60,80$, and $100 \mu \mathrm{M}$. A standard curve was generated by plotting absorbance values for Trolox at selected concentrations. Standard curve for Trolox is linear between 25 and $800 \mu \mathrm{M}$ Trolox [18]. Results were expressed in terms of Troloxequivalent antioxidant capacity (TEAC), i.e., $\mu \mathrm{molTrolox} / \mathrm{g}$ dry mass (DM).

Antioxidant capacity was calculated from the standard curve and

\begin{tabular}{|l|c|c|}
\hline Ingredient $(\% \mathrm{w} / \mathrm{w})$ & Control & Fortified \\
\hline flour & 40 & 36 \\
\hline Granulated sugar & 4.5 & 4 \\
\hline Salt & 0.5 & 0.5 \\
\hline Baking Powder (double action) & 2 & 2 \\
\hline Vegetable oil & 4.3 & 4 \\
\hline $2 \%$ reduced fat Milk & 40 & 35.5 \\
\hline Raw Egg white & 8.7 & 8 \\
\hline Freeze dried blueberry powder (BP) & $X$ & 10 \\
\hline Total & 100 & 100 \\
\hline
\end{tabular}

Table 1a: Muffin formulations

\begin{tabular}{|l|c|c|}
\hline Ingredient $(\% \mathrm{w} / \mathrm{w})$ & Control & Fortified \\
\hline flour & 30 & 26.23 \\
\hline Brown sugar & 21 & 19.27 \\
\hline Salt & 0.7 & 0.65 \\
\hline Baking Powder (double action) & 0.3 & 0.26 \\
\hline Unsalted Butter & 16 & 14.68 \\
\hline Nonfat Dry Milk & 21 & 18.82 \\
\hline Whole Egg & 11 & 10.09 \\
\hline Freeze dried blueberry powder (BP) & $\mathrm{X}$ & 10 \\
\hline Total & 100 & 100 \\
\hline
\end{tabular}

Table 1b: Cookies formulations 
expressed as $\mu$ molTrolox equivalent (TE) $\mathrm{g}^{-1} \mathrm{DM}$ according to the following equation: $\left.g_{\text {sample }}\right)$

Antioxidant capacity $\left(\mu \mathrm{mol} \mathrm{TE} \mathrm{g}^{-1}\right)=\left(\mu \mathrm{mol} \mathrm{L} \mathrm{L}^{-1}\right) \times \mathrm{DF} \times\left(L_{\text {solvent }}{ }^{\prime}\right.$

Where DF is the dilution factor of methanol extract, $L_{\text {solvent }}$ is the volume of solvent used for extraction of the experimental freeze dried blueberry powder, batter or muffin and $g_{\text {sample }}$ is the mass of batter or muffin used for extraction.

\section{Measurements were done thrice.}

Determination of Total Phenolic content: Total phenolic content was determined using a modified [19] Folin-Ciocalteu procedure. Briefly a $0.5-\mathrm{mL}$ of the sample extract or a series of gallic acid standards $(0,20,40,60,80$, and $100 \mathrm{mg} / \mathrm{l})$ were mixed with 0.5 $\mathrm{mL}$ of the Folin-Ciocalteu reagent (Sigma Chemical Co., St. Louis, Mo., U.S.A.) and $7.5 \mathrm{~mL}$ deionized water. The mixture was held at room temperature for 10 min before adding $1.5 \mathrm{~mL}$ of $20 \%$ sodium carbonate $(\mathrm{w} / \mathrm{v})$. The mixtures were heated in a $40^{\circ} \mathrm{C}$ water bath for 20 min and then immediately cooled in an ice bath before measuring the absorbance at $750 \mathrm{~nm}$. Results were expressed as milligrams of gallic acid equivalent per gram of dry mass (GAE/g DM). Absorbance was recorded in a Spectrophotometer (Spectronics 20, Spectronics, CA). All measurements were done in triplicate.

Determination of Total Anthocyanin Content: The total anthocyanin content of berries was determined using a modified $\mathrm{pH}$ differential method [20]. Briefly, $1 \mathrm{~mL}$ of clear extract was placed into a $25 \mathrm{ml}$ volumetric flask, made up to a final volume with two different buffers at $\mathrm{pH} 1.00$ and $\mathrm{pH}$ 4.5. Buffers were prepared in 0.025 $\mathrm{M}$ potassium chloride solution and in $0.4 \mathrm{M}$ sodium acetate solution adjusted respectively to $\mathrm{pH} 1.0$ and 4.5 with $\mathrm{HCl}$. Mixture absorbance were recorded at $510 \mathrm{~nm}$ for $\mathrm{pH} 1.00$ and at $700 \mathrm{~nm}$ for $\mathrm{pH} 4.5$ in a Spectrophotometer (Spectronics 20, Spectronics, CA).

Absorbance were calculated as $\Delta \mathrm{A}=\left(\mathrm{A}_{510 \mathrm{~nm}}-\mathrm{A}_{700 \mathrm{~nm}}\right) \mathrm{pH}_{1.0}-\left(\mathrm{A}_{510 \mathrm{~nm}}\right.$ - $\left.\mathrm{A}_{700 \mathrm{~nm}}\right) \mathrm{pH}_{4.5}$

Results were calculated using the following equation and expressed as milligrams of cyanidin 3-glucoside equivalents per gram of dry basis weight:-

Total anthocyanins $(\mathrm{mg} / \mathrm{g})=(\Delta \mathrm{A} / \varepsilon \mathrm{L})$ X MW X D X $(\mathrm{V} / \mathrm{G})$,

Where $\Delta \mathrm{A}$ is absorbance, as calculated by the above relation, $\varepsilon$ is the molar extinction coefficient for cyanidin 3-glucoside (which is $26,900), \mathrm{L}$ is the cell path length $(1 \mathrm{~cm}), \mathrm{D}$ is the dilution factor, $\mathrm{V}$ is the final volume of the mixture in $\mathrm{ml}$ and $\mathrm{G}$ is the sample weight in gm.

Extracts were analysed in triplicate.

Texture Profile Analysis (TPA): The textural properties of muffins and cookies were determined using a TA.XT Plus Texture Analyzer (Texture Technologies Corp., Scarsdale, NY) (Stable Micro Systems Ltd.). Cubes of $2.5 \mathrm{~cm}$ were gently cut out of the center of each muffin with a serrated bread knife to expose the crumb for texture measurement. Crumb texture measurement was performed by Texture Profile Analysis (TPA) using a TA-25 MUF1/P36R probe and a TA90 platform, with pretest speed $=5 \mathrm{~mm} / \mathrm{s}$, test speed $=1 \mathrm{~mm} / \mathrm{s}$, post test speed $=2 \mathrm{~mm} / \mathrm{s}$ and distance $=10 \mathrm{~mm}$. Texture analysis program parameters were set as follows: pretest speed $=5 \mathrm{~mm} / \mathrm{s}$; test speed $=1$ $\mathrm{mm} / \mathrm{s}$; post-test speed $=2 \mathrm{~mm} / \mathrm{s}$; test distance of $5 \mathrm{~mm}$; and distance of $10 \mathrm{~mm}$. Textural variables from force and area measurements (6) were: hardness=peak force (g) during the first compression cycle; cohesiveness=ratio of the positive force area during the second compression to that during the first compression; springiness=height that the sample recovers during the time that elapses between the end of the first bite and the start of the second bite $(\mathrm{cm})$; and chewiness= hardness X cohesiveness X springiness $(\mathrm{g} \mathrm{cm})$. Three muffins from each formulation were used to evaluate textural parameters.

Cookie hardness and fracturability were measured using a threepoint bending test, using a three point bending, $\mathrm{HDP} / 3 \mathrm{~PB}$ cookies probe. The hardness of cookies was indicated by the maximum peak force required to break them. The texture analyzer, was fitted with sharp-blade probe, $6 \mathrm{~cm}$ long and $1 \mathrm{~mm}$ thick, and was set to 'return to start' cycle, a pretest speed of $1.0 \mathrm{~mm} / \mathrm{s}$, test speed of $3.0 \mathrm{~mm} / \mathrm{s}$, posttest speed of $10 \mathrm{~mm} / \mathrm{s}$, and a distance of $5.0 \mathrm{~mm}$. Textural variables measured were hardness (force in g) and fracturability (distance in $\mathrm{mm}$ ). Three cookies from each formulation were used to evaluate textural parameters.

\section{Sensory evaluation}

A panel of 20 semi-trained judges of both genders, ages 18-50 years evaluated the muffins on a 9-point hedonic scale (1=dislike extremely, $5=$ neither like nor dislike, $9=$ =like extremely) [14]. Muffins and cookies were sliced into half and identified by a three-digit random number. The samples were offered to the judges on a white plate at room temperature in individual booths under white light. Panelists were given room temperature water to cleanse their palate before tasting the samples from each formulation. All six samples were served, one at a time, to each panelist. Appearance, flavor, texture, sweetness and overall acceptability were evaluated using an attribute rating scorecard.

\section{Statistical analysis}

Three samples from each of the 4 batches for each treatment (control and variations) were used for all measurements. All data $(\mathrm{n}=12)$ were analyzed using Statistical Analysis System (SAS Institute, Inc, Version 9.1.3, Cary, NC) and were subjected to analysis of variance with Fisher's least significant test for mean separation at 0.05 level of probability.

\section{Results and Discussions}

\section{Moisture properties of muffins and cookies}

Moisture and water activity are two important physical properties of muffins and cookies and their qualities depend on these two physical properties. Table $2 \mathrm{a}$ and $2 \mathrm{~b}$ represent moisture properties and Table $3 \mathrm{a}$ and $3 \mathrm{~b}$ represent water activities for unfortified and blueberry powder fortified muffins and cookies after storage. Four different storage times were used: day 0 , month 1 , month 2 and month 3 . One of its many novel functional properties of Quinoa is its Water Holding Capacity (WHC) specific for pseudo cereals [21]. Therefore, as expected, moisture content, and water activity increased with storage but fortification with blueberry powder prevented this increase in both muffins and cookies. When comparing flours with and without fortification, blueberry powder decreased the moisture content and water activities of muffins, but the reverse was seen in case of cookies. The reasons for these differences are not clear, but they might be due to the differences in their dough compositions, baking time and temperature conditions. Storage did not typically increase moisture content for unfortified products until 2 months. Most baked products experience a rapid increase of moisture content in the first 3 days and show smaller changes in their moisture content after that [22]. 
Citation: Bhaduri S, Navder KP (2014) Freeze Dried Blueberry Powder Fortification Improves the Quality of Gluten Free Snacks. J Food Process Technol 5: 396. doi:10.4172/2157-7110.1000396

Page 4 of 7

\begin{tabular}{|c|c|c|c|c|}
\hline Flour formulation (for muffins) & Day 0 & Month 1 & Month 2 & Month 3 \\
\hline $100 \%$ Rice flour & $24.54 \pm 0.38^{a}$ & $24.71 \pm 0.41^{\mathrm{a}}$ & $25.04 \pm 0.22^{b}$ & $27.03 \pm 0.19^{c}$ \\
\hline $100 \%$ Rice flour $+10 \%$ BP & $22.55 \pm 0.07^{\mathrm{b}}$ & $22.35 \pm 0.05^{b}$ & $21.79 \pm 0.05 c$ & $21.11 \pm 0.06^{d}$ \\
\hline $50 \%$ Rice flour $+50 \%$ Quinoa flour & $24.08 \pm 0.04^{c}$ & $24.24 \pm 0.08^{c}$ & $25.35 \pm 0.07^{d}$ & $26.47 \pm 0.06^{\mathrm{e}}$ \\
\hline $50 \%$ Rice flour $+50 \%$ Quinoa flour $+10 \%$ BP & $23.41 \pm 0.06^{d}$ & $22.68 \pm 0.09^{h}$ & $21.57 \pm 0.07^{c}$ & $20.24 \pm 0.08^{f}$ \\
\hline $100 \%$ Quinoa flour & $26.61 \pm 0.07^{e}$ & $26.75 \pm 0.08^{\mathrm{e}}$ & $28.29 \pm 0.05^{\mathrm{a}}$ & $29.82 \pm 0.06^{9}$ \\
\hline $100 \%$ Quinoa flour+ $10 \%$ BP & $25.64 \pm 0.08^{f}$ & $25.22 \pm 0.06^{g}$ & $24.98 \pm 0.06^{b}$ & $24.85 \pm 0.08^{h}$ \\
\hline
\end{tabular}

Results are expressed as Mean \pm Standard deviation. Values with different superscripts $(a, b, c, d, e, f, g, h)$ in a column differ significantly ( $<<0.05)$.

Table 2a: Moisture content with time due to freeze-dried blueberry powder fortification in muffins

\begin{tabular}{|c|c|c|c|c|}
\hline Flour formulation (for cookies) & Day 0 & Month 1 & Month 2 & Month 3 \\
\hline $100 \%$ Rice flour & $12.92 \pm 0.05^{a}$ & $14.84 \pm 0.03^{c}$ & $15.27 \pm 0.06^{d}$ & $16.27 \pm 0.07^{\mathrm{e}}$ \\
\hline $100 \%$ Rice flour $+10 \%$ BP & $15.33 \pm 0.08^{b}$ & $15.37 \pm 0.07^{b}$ & $15.56 \pm 0.05^{b}$ & $15.98 \pm 0.05^{c}$ \\
\hline $50 \%$ Rice flour $+50 \%$ Quinoa flour & $14.48 \pm 0.05^{c}$ & $14.51 \pm 0.04^{c}$ & $16.24 \pm 0.04^{\mathrm{a}}$ & $18.61 \pm 0.03^{b}$ \\
\hline $50 \%$ Rice flour $+50 \%$ Quinoa flour $+10 \%$ BP & $21.26 \pm 0.16^{d}$ & $21.02 \pm 0.12^{\mathrm{d}}$ & $20.82 \pm 0.14^{e}$ & $20.48 \pm 0.14^{a}$ \\
\hline 100\% Quinoa flour & $12.45 \pm 0.35^{\mathrm{e}}$ & $12.57 \pm 0.33^{e}$ & $14.01 \pm 0.35^{c}$ & $15.23 \pm 0.18^{d}$ \\
\hline $100 \%$ Quinoa flour+ $10 \%$ BP & $22.68 \pm 0.44^{f}$ & $21.86 \pm 0.54^{g}$ & $21.56 \pm 0.24^{\mathrm{h}}$ & $21.25 \pm 0.45^{i}$ \\
\hline
\end{tabular}

Results are expressed as Mean \pm Standard deviation. Values with different superscripts $(a, b, c, d, e, f, g, h, i)$ in a column differ significantly ( $p<0.05)$.

Table 2b: Moisture content with time due to freeze-dried blueberry powder fortification in cookies

\begin{tabular}{|l|c|c|c|}
\hline Flour formulation (for muffins) & Day 0 & Month 1 & Month 2 \\
\hline $100 \%$ Rice flour & $0.835 \pm 0.025^{\mathrm{a}}$ & $0.906 \pm 0.007^{\mathrm{c}}$ & $0.927 \pm 0.013^{\mathrm{d}}$ \\
\hline $100 \%$ Rice flour + 10\% BP & $0.839 \pm 0.012^{\mathrm{b}}$ & $0.826 \pm 0.011^{\mathrm{b}}$ & $0.923 \pm 0.018^{\mathrm{e}}$ \\
\hline $50 \%$ Rice flour + 50\% Quinoa flour & $0.822 \pm 0.011^{\mathrm{a}}$ & $0.937 \pm 0.01^{\mathrm{e}}$ & $0.821 \pm 0.008^{\mathrm{f}}$ \\
\hline $50 \%$ Rice flour + 50\% Quinoa flour + 10\% BP & $0.823 \pm 0.007^{\mathrm{a}}$ & $0.821 \pm 0.008^{\mathrm{a}}$ & $0.009^{\mathrm{a}}$ \\
\hline $100 \%$ Quinoa flour & $0.816 \pm 0.006^{\mathrm{a}}$ & $0.939 \pm 0.004^{\mathrm{d}}$ & $0.815 \pm 0.007^{\mathrm{a}}$ \\
\hline $100 \%$ Quinoa flour+ 10\% BP & $0.781 \pm 0.006^{\mathrm{c}}$ & $0.778 \pm 0.005^{\mathrm{c}}$ & $0.939 \pm 0.005^{\mathrm{e}}$ \\
\hline
\end{tabular}

Results are expressed as Mean \pm Standard deviation.. Values with different superscripts $(a, b, c, d, e, f, g, h)$ in a column differ significantly ( $p<0.05)$.

Table 3a: Water activities $\left(A_{w}\right)$ with time due to freeze-dried blueberry powder fortification in muffins

\begin{tabular}{|l|c|c|c|}
\hline Flour formulation (for cookies) & Day 0 & Month 1 & Month 2 \\
\hline $100 \%$ Rice flour & $0.254 \pm 0.004^{\mathrm{a}}$ & $0.301 \pm 0.005^{\mathrm{c}}$ & $0.311 \pm 0.006^{\mathrm{b}}$ \\
\hline $100 \%$ Rice flour + 10\% BP & $0.498 \pm 0.001^{\mathrm{b}}$ & $0.503 \pm 0.002^{\mathrm{b}}$ & $0.321 \pm 0.007^{\mathrm{d}}$ \\
\hline $50 \%$ Rice flour + 50\% Quinoa flour & $0.425 \pm 0.006^{\mathrm{c}}$ & $0.428 \pm 0.003^{\mathrm{a}}$ & $0.523 \pm 0.006^{\mathrm{c}}$ \\
\hline $50 \%$ Rice flour + 50\% Quinoa flour + 10\% BP & $0.579 \pm 0.005^{\mathrm{d}}$ & $0.569 \pm 0.005^{\mathrm{f}}$ & $0.438 \pm 0.005^{\mathrm{d}}$ \\
\hline $100 \%$ Quinoa flour & $0.346 \pm 0.003^{\mathrm{e}}$ & $0.348 \pm 0.002^{\mathrm{e}}$ & $0.549 \pm 0.006^{\mathrm{g}}$ \\
\hline $100 \%$ Quinoa flour+ 10\% BP & $0.599 \pm 0.004^{\mathrm{f}}$ & $0.589 \pm 0.004^{\mathrm{g}}$ & $0.521 \pm 0.006^{\mathrm{h}}$ \\
\hline
\end{tabular}

Results are expressed as Mean \pm Standard deviation.. Values with different superscripts $(a, b, c, d, e, f, g, h, i, j)$ in a column differ significantly ( $<<0.05)$

Table 3b: Water activities $\left(A_{w}\right)$ with time due to freeze-dried blueberry powder fortification in cookies

\section{Microbiological analysis}

No microbiological growth was observed up to three months of regular refrigeration storage for Quinoa flour and the blueberry powder fortified muffins and cookies. A few colonies were observed in unfortified Rice flour products after 2 months, but those were not analyzed in detail in this study. Reduced moisture content and water activities for the blueberry powder fortified products perhaps prevented microbiological growth. Additional work needs to be done to explore this.

\section{Antioxidant capacity, total phenolic and total anthocyanin content assays}

Table 4a and 4b represent Antioxidant activities of fortified and unfortified muffin and cookies. Blueberries, like all berries are believed to be a rich source of polyphenol and anthocyanin like antioxidants [23]. Blueberry fortification was found to bring about a significant increase in the antioxidant capacity, but baking was found to bring about a reduction. Quinoa flour is also an excellent source of antioxidant compounds [5], and Quinoa like pseudocereals have been shown to have a higher content of anthocyanin compounds [24]. Similar results were seen in this study where muffins and cookies made with Quinoa flour had higher antioxidant and anthocyanin content than rice flour.

A $137 \%$ increase in antioxidant activity was observed in $100 \%$ Quinoa flour muffins compared to $100 \%$ Rice flour muffins (Table 4a). Total phenolic content and total anthocyanin contents were also the highest (0.185 GAE per g DM and 0.136 C3G per g DM) in $100 \%$ Quinoa flour muffins after freeze dried blueberry powder fortification. Blueberry powder fortified 100\% Quinoa flour cookies showed highest total phenolic content $(0.315 \mathrm{GAE}$ per $\mathrm{g} \mathrm{DM})$, total anthocyanin content (0.204 C3G per g DM) and antioxidant activity $(334.16 \mu \mathrm{mol}$ TE per $\mathrm{g}$ DM) compared to other two flour formulated cookies after blueberry powder fortification. However, not a big difference in percentage increase of activity was observed for all three flour formulations, with fortification (Table 4b).

\section{Texture properties}

Tables 5a show the texture properties of fortified and unfortified muffins. Significant change in texture was observed in both muffins and cookies when rice flour was replaced by Quinoa flour. Quinoa 
Citation: Bhaduri S, Navder KP (2014) Freeze Dried Blueberry Powder Fortification Improves the Quality of Gluten Free Snacks. J Food Process Technol 5: 396. doi:10.4172/2157-7110.1000396

Page 5 of 7

\begin{tabular}{|c|c|c|c|c|}
\hline $\begin{array}{l}\text { Flour formulations } \\
\text { (for muffins) }\end{array}$ & Reaction gradient & $\begin{array}{l}\text { Antioxidant activity } \\
\text { ( } \mu \text { mol TE per g DM) }\end{array}$ & $\begin{array}{l}\text { Total phenolic content } \\
\text { (mg GAE per g DM) }\end{array}$ & $\begin{array}{l}\text { Total anthocyanin content } \\
\text { (mg C3G per g DM) }\end{array}$ \\
\hline \multirow{3}{*}{$100 \%$ Rice flour } & Before baking & $149 \pm 3.61^{\mathrm{h}}$ & $0.028 \pm 0.004^{9}$ & $0.038 \pm 0.008^{h}$ \\
\hline & After baking & $140 \pm 1.73^{9}$ & $0.025 \pm 0.004^{9}$ & $0.027 \pm 0.004^{9}$ \\
\hline & $\%$ Loss in activity after baking & $5.99 \pm 3.21^{m}$ & $11.12 \pm 4.87$ & $28.16 \pm 5.38^{\mathrm{m}}$ \\
\hline \multirow{4}{*}{$\begin{array}{l}100 \% \text { Rice flour }+10 \% \\
\text { BP }\end{array}$} & Before baking & $255 \pm 5.56^{f}$ & $0.201 \pm 0.011^{f}$ & $0.1 \pm 0.005^{f}$ \\
\hline & After baking & $244 \pm 2.64^{\mathrm{e}}$ & $0.175 \pm 0.005^{\mathrm{e}}$ & $0.058 \pm 0.006^{e}$ \\
\hline & $\%$ Loss in activity after baking & $4.27 \pm 3.04^{\mathrm{m}}$ & $13.01 \pm 2.21^{\mathrm{m}}$ & $42.11 \pm 2.96^{n}$ \\
\hline & $\%$ increase of activity after fortification in baked product & $74.31 \pm 3.66^{n}$ & $615.04 \pm 125.55^{n}$ & $41.07 \pm 1.35^{\circ}$ \\
\hline \multirow{3}{*}{$\begin{array}{l}\mathbf{5 0 \%} \text { Rice flour }+\mathbf{5 0} \% \\
\text { Quinoa flour }\end{array}$} & Before baking & $98.3 \pm 2.51^{1}$ & $0.067 \pm 0.003^{k}$ & $0.095 \pm 0.005$ \\
\hline & After baking & $92.5 \pm 1.51^{k}$ & $0.06 \pm 0.004^{k}$ & $0.067 \pm 0.004^{k}$ \\
\hline & $\%$ Loss after baking & $5.91 \pm 2.24^{\mathrm{m}}$ & $10.51 \pm 2.02$ & $28.68 \pm 0.91^{m}$ \\
\hline \multirow{4}{*}{$\begin{array}{l}50 \% \text { Rice flour }+50 \% \\
\text { Quinoa flour }+10 \% \text { BP }\end{array}$} & Before baking & $212.6 \pm 2.08^{j}$ & $0.194 \pm 0.004$ & $0.162 \pm 0.009$ \\
\hline & After baking & $204 \pm 3.61^{i}$ & $0.17 \pm 0.002$ & $0.094 \pm 0.005^{i}$ \\
\hline & $\%$ Loss in activity after baking & $4.08 \pm 0.75^{\mathrm{m}}$ & $12.34 \pm 1.81^{\mathrm{m}}$ & $41.96 \pm 1.04^{n}$ \\
\hline & $\%$ increase of activity after fortification in baked product & $120.54 \pm 0.96^{\circ}$ & $184.28 \pm 18.68^{\circ}$ & $40.30 \pm 1.29^{\circ}$ \\
\hline \multirow[t]{3}{*}{$100 \%$ Quinoa flour } & Before baking & $91.7 \pm 4.51^{\mathrm{c}}$ & $0.057 \pm 0.007^{c}$ & $0.143 \pm 0.01^{d}$ \\
\hline & After baking & $86.6 \pm 1.52^{c}$ & $0.05 \pm 0.005^{c}$ & $0.102 \pm 0.004^{c}$ \\
\hline & $\%$ Loss after baking & $5.35 \pm 3.01^{\mathrm{m}}$ & $12.05 \pm 2.95^{\prime}$ & $28.56 \pm 2.33^{m}$ \\
\hline \multirow{4}{*}{$\begin{array}{l}100 \% \text { Quinoa flour }+ \\
10 \% \text { BP }\end{array}$} & Before baking & $214 \pm 1.52^{b}$ & $0.211 \pm 0.01^{b}$ & $0.234 \pm 0.007^{b}$ \\
\hline & After baking & $206 \pm 2.64^{a}$ & $0.185 \pm 0.017^{\mathrm{a}}$ & $0.136 \pm 0.005^{a}$ \\
\hline & $\%$ Loss after baking & $4.03 \pm 1.41^{\mathrm{m}}$ & $12.44 \pm 4.51^{\prime}$ & $41.88 \pm 0.59^{n}$ \\
\hline & $\%$ increase of activity after fortification in baked product & $137.73 \pm 4.14^{\mathrm{p}}$ & $270.94 \pm 24.76^{\circ}$ & $66.01 \pm 8.33^{p}$ \\
\hline
\end{tabular}

Results are expressed as Mean \pm Standard deviation.. Values with different superscripts $(a, b, c, d, e, f, g, h, i, j, k, l, m, n, o, p)$ in a column differ significantly ( $p<0.05)$. Table 4a: Antioxidant properties of muffins due to fortification with freeze-dried blueberry power

\begin{tabular}{|c|c|c|c|c|}
\hline $\begin{array}{l}\text { Flour formulations (for } \\
\text { cookies) }\end{array}$ & Reaction gradient & $\begin{array}{l}\text { Antioxidant activity } \\
\text { ( } \mu \text { mol TE per g DM) }\end{array}$ & $\begin{array}{l}\text { Total phenolic content } \\
\text { (mg GAE per g DM) }\end{array}$ & $\begin{array}{l}\text { Total anthocyanin content } \\
\text { (mg C3G per g DM) }\end{array}$ \\
\hline \multirow{3}{*}{$100 \%$ Rice flour } & Before baking & $128.8 \pm 6.48^{f}$ & $0.196 \pm 0.009^{f}$ & $0.164+0.012^{h}$ \\
\hline & After baking & $121 \pm 4.19^{f}$ & $0.175 \pm 0.007^{f}$ & $0.117 \pm 0.006^{g}$ \\
\hline & $\%$ Loss in activity after baking & $6.01 \pm 2.11^{i}$ & $10.64 \pm 3.73^{j}$ & $28.57 \pm 1.77^{\mathrm{m}}$ \\
\hline \multirow{4}{*}{$\begin{array}{l}100 \% \text { Rice flour }+10 \% \\
\text { BP }\end{array}$} & Before baking & $179.26 \pm 6.54^{\mathrm{e}}$ & $0.297 \pm 0.038^{\mathrm{e}}$ & $0.284 \pm 0.013^{f}$ \\
\hline & After baking & $172.16 \pm 6.29 \mathrm{e}$ & $0.261 \pm 0.046^{d}$ & $0.165 \pm 0.007^{e}$ \\
\hline & $\%$ Loss in activity after baking & $3.95 \pm 0.87^{j}$ & $12.34 \pm 7.08^{k}$ & $41.89 \pm 0.31^{n}$ \\
\hline & $\%$ increase of activity after fortification in baked product & $42.31 \pm 4.19^{k}$ & $31.69 \pm 8.75^{\prime}$ & $52.09 \pm 9.21^{\circ}$ \\
\hline \multirow{3}{*}{$\begin{array}{l}\mathbf{5 0 \%} \text { Rice flour }+\mathbf{5 0 \%} \\
\text { Quinoa flour }\end{array}$} & Before baking & $161.67 \pm 7.91^{\mathrm{h}}$ & $0.252 \pm 0.008^{j}$ & $0.156 \pm 0.014$ \\
\hline & After baking & $152.06 \pm 3.49^{h}$ & $0.225 \pm 0.004$ & $0.111 \pm 0.006^{k}$ \\
\hline & $\%$ Loss in activity after baking & $5.86 \pm 2.48^{i}$ & $10.68 \pm 1.72^{j}$ & $28.71 \pm 2.38^{m}$ \\
\hline \multirow{4}{*}{$\begin{array}{l}50 \% \text { Rice flour }+50 \% \\
\text { Quinoa flour }+10 \% \text { BP }\end{array}$} & Before baking & $208.42 \pm 7.22^{\mathrm{g}}$ & $0.325 \pm 0.007^{\mathrm{h}}$ & $0.251 \pm 0.013^{j}$ \\
\hline & After baking & $200.06 \pm 9.14^{g}$ & $0.285 \pm 0.012^{g}$ & $0.146 \pm 0.006^{i}$ \\
\hline & $\%$ Loss in activity after baking & $4.02 \pm 2.11^{j}$ & $12.32 \pm 2.71^{k}$ & $41.81 \pm 1.35^{n}$ \\
\hline & $\%$ increase of activity after fortification in baked product & $49.04 \pm 21.36^{k}$ & $26.70 \pm 6.09^{m}$ & $40.04 \pm 5.01^{\mathrm{p}}$ \\
\hline \multirow[t]{3}{*}{$100 \%$ Quinoa flour } & Before baking & $233.83 \pm 10.71^{d}$ & $0.252 \pm 0.013^{c}$ & $0.173 \pm 0.026^{d}$ \\
\hline & After baking & $220.04 \pm 9.22^{c}$ & $0.225 \pm 0.005^{c}$ & $0.123 \pm 0.007^{c}$ \\
\hline & $\%$ Loss in activity after baking & $5.88 \pm 0.54$ & $10.62 \pm 2.63^{j}$ & $28.22 \pm 6.55^{\mathrm{m}}$ \\
\hline \multirow{4}{*}{$\begin{array}{l}100 \% \text { Quinoa flour + } \\
10 \% \text { BP }\end{array}$} & Before baking & $347.67 \pm 6.02^{\mathrm{b}}$ & $0.361 \pm 0.009^{b}$ & $0.352 \pm 0.011^{b}$ \\
\hline & After baking & $334.16 \pm 9.82^{\mathrm{a}}$ & $0.315 \pm 0.011^{\mathrm{a}}$ & $0.204 \pm 0.011^{\mathrm{a}}$ \\
\hline & $\%$ Loss in activity after baking & $3.87 \pm 2.88 \mathrm{j}$ & $12.75 \pm 0.74^{k}$ & $42.05 \pm 2.12^{n}$ \\
\hline & $\%$ increase of activity after fortification in baked product & $41.07 \pm 1.35^{k}$ & $31.62 \pm 3.66^{\prime}$ & $66.01 \pm 8.33^{q}$ \\
\hline
\end{tabular}

Results are expressed as Mean \pm Standard deviation.. Values with different superscripts $(a, b, c, d, e, f, g, h, i, j, k, l, m, n, o, p, q)$ in a column differ significantly ( $p<0.05)$.

Table 4b: Antioxidant properties of cookies due to fortification with freeze-dried blueberry power

flour products had increased hardness due to its high fiber content. The final volume of baked products is based on a two-step process. The first involves incorporation of air in the batter during mixing which depends on the viscosity of the batter and mixing conditions. The second expansion occurs during baking when the incorporated air and the carbon dioxide produced from leavening agents expand causing the elastic batter to further extend.
The $100 \%$ unfortified Rice flour muffins were the softest $(868.27 \mathrm{~g}$ ) while the $100 \%$ fortified Quinoa flour muffins were the hardest (1737.97 g). This was expected since Quinoa flour has a higher bulk volume compared to Rice flour which also reduces the moisture content. Increased hardness reduced the springiness in muffins. Quinoa flour fortification also increased the chewiness and gumminess in muffins. Blueberry powder fortification was found to increase hardness, and 
Citation: Bhaduri S, Navder KP (2014) Freeze Dried Blueberry Powder Fortification Improves the Quality of Gluten Free Snacks. J Food Process Technol 5: 396. doi:10.4172/2157-7110.1000396

Page 6 of 7

\begin{tabular}{|c|c|c|c|c|c|}
\hline Flour formulations (for muffins) & Hardness (g) & Springiness (cm) & Cohesiveness & Gumminess & Chewiness $(\mathrm{g} \mathrm{cm})$ \\
\hline $100 \%$ Rice flour & $868.27 \pm 20.33^{a}$ & $0.906 \pm 0.09^{a}$ & $0.784 \pm 0.02^{\mathrm{a}}$ & $229.52 \pm 21.51^{\mathrm{a}}$ & $781.20 \pm 33.69^{a}$ \\
\hline $100 \%$ Rice flour $+10 \%$ BP & $1096.21 \pm 21.09^{b}$ & $0.657 \pm 0.153^{b}$ & $0.824 \pm 0.19^{a}$ & $272.06 \pm 12.57^{\mathrm{a}}$ & $668.03 \pm 43.64^{a}$ \\
\hline $50 \%$ Rice flour $+\mathbf{5 0} \%$ Quinoa flour & $1079.12 \pm 54.56^{a}$ & $1.006 \pm 0.06^{a}$ & $0.842 \pm 0.03^{a}$ & $645.79 \pm 43.27^{\mathrm{b}}$ & $1079.00 \pm 33.04^{b}$ \\
\hline $50 \%$ Rice flour $+50 \%$ Quinoa flour $+10 \%$ BP & $1137.82 \pm 84.51^{\mathrm{c}}$ & $0.844 \pm 0.05^{c}$ & $0.861 \pm 0.06^{\mathrm{a}}$ & $626.56 \pm 45.44^{b}$ & $1171.51 \pm 88.93^{b}$ \\
\hline $100 \%$ Quinoa flour & $1478.28 \pm 30.46^{a}$ & $1.040 \pm 0.05^{a}$ & $0.790 \pm 0.04^{a}$ & $1015.45 \pm 23.43^{c}$ & $1537.00 \pm 24.24^{\mathrm{c}}$ \\
\hline $100 \%$ Quinoa flour+ $10 \%$ BP & $1737.97 \pm 44.92^{\mathrm{a}}$ & $1.006 \pm 0.01^{\mathrm{a}}$ & $0.834 \pm 0.06^{a}$ & $1007.51 \pm 9.54^{c}$ & $1232.22 \pm 112.65^{\mathrm{b}}$ \\
\hline
\end{tabular}

Results are expressed as Mean \pm Standard deviation.. Values with different superscripts $(a, b, c)$ in a column differ significantly ( $p<0.05)$.

Table 5a: Texture properties of unfortified and freeze-dried blueberry powder fortified muffins

\begin{tabular}{|l|c|c|}
\hline Flour formulations (for cookies) & Hardness (g) & Fracturability \\
\hline $\mathbf{1 0 0} \%$ Rice flour & $343.81 \pm 6.06^{\mathrm{a}}$ & $39.9 \pm 1.69^{\mathrm{a}}$ \\
\hline $\mathbf{1 0 0} \%$ Rice flour $\mathbf{1 0} \%$ BP & $568.86 \pm 11.49^{\mathrm{b}}$ & $41.65 \pm 2.45^{\mathrm{a}}$ \\
\hline $\mathbf{5 0} \%$ Rice flour $+\mathbf{5 0} \%$ Quinoa flour & $365.61 \pm 10.03^{\mathrm{a}}$ & $38.34 \pm 2.52^{\mathrm{a}}$ \\
\hline $\mathbf{5 0} \%$ Rice flour $+\mathbf{5 0} \%$ Quinoa flour $+\mathbf{1 0} \%$ BP & $725.41 \pm 34.34^{\mathrm{c}}$ & $40.66 \pm 7.21^{\mathrm{a}}$ \\
\hline $\mathbf{1 0 0} \%$ Quinoa flour & $503.79 \pm 19.89^{\mathrm{b}}$ & $38.32 \pm 6.85^{\mathrm{a}}$ \\
\hline $\mathbf{1 0 0} \%$ Quinoa flour+ 10\% BP & $830.24 \pm 19.96^{\mathrm{a}}$ & $38.11 \pm 4.07^{\mathrm{a}}$ \\
\hline
\end{tabular}

Results are expressed as Mean \pm Standard deviation.. Values with different superscripts $(a, b, c)$ in a column differ significantly ( $<<0.05)$

Table 5 b: Texture properties of unfortified and freeze-dried blueberry powder fortified cookies

\begin{tabular}{|c|c|c|c|c|c|}
\hline Flour formulations (for muffins) & Flavor & Texture & Sweetness & Appearance & Overall acceptance \\
\hline $100 \%$ Rice flour & $7.38 \pm 0.59^{\mathrm{a}}$ & $7.14 \pm 0.35^{\mathrm{a}}$ & $6.04 \pm 3.66^{\mathrm{a}}$ & $6.81 \pm 0.61^{\mathrm{a}}$ & $7.04 \pm 0.49^{\mathrm{a}}$ \\
\hline $100 \%$ Rice flour $+10 \% \mathrm{BP}$ & $7.71 \pm 0.46^{\mathrm{a}}$ & $7.23 \pm 0.43^{\mathrm{a}}$ & $6.63 \pm 3.98^{\mathrm{b}}$ & $6.57 \pm 0.51^{\mathrm{a}}$ & $7.85 \pm 0.79^{b}$ \\
\hline $50 \%$ Rice flour $+50 \%$ Quinoa flour & $6.28 \pm 0.56^{c}$ & $6.52 \pm 0.61^{b}$ & $4.99 \pm 3.06^{\mathrm{d}}$ & $6.14 \pm 0.72^{b}$ & $6.14 \pm 0.85^{c}$ \\
\hline $50 \%$ Rice flour $+50 \%$ Quinoa flour $+10 \%$ BP & $6.38 \pm 0.49^{c}$ & $6.23 \pm 0.43^{c}$ & $5.11 \pm 3.09^{d}$ & $6.52 \pm 0.61^{\mathrm{a}}$ & $6.04 \pm 0.21^{c}$ \\
\hline $100 \%$ Quinoa flour & $6.52 \pm 0.63^{b}$ & $5.71 \pm 0.46^{d}$ & $5.13 \pm 3.11^{c}$ & $6.14 \pm 0.79^{b}$ & $6.23 \pm 0.43^{c}$ \\
\hline $100 \%$ Quinoa flour+ $10 \%$ BP & $6.04 \pm 0.66^{d}$ & $5.14 \pm 0.38^{d}$ & $4.25 \pm 2.57^{c}$ & $6.23 \pm 1.17^{b}$ & $5.28 \pm 0.78^{d}$ \\
\hline
\end{tabular}

Results are expressed as Mean \pm Standard deviation.. Values with different superscripts $(a, b, c, d)$ in a column differ significantly ( $p<0.05)$.

Table 6a: Sensory characteristics of unfortified and freeze-dried blueberry powder fortified muffins

\begin{tabular}{|c|c|c|c|c|c|}
\hline Flour formulations (for cookies) & Flavor & Texture & Sweetness & Appearance & Overall acceptance \\
\hline $100 \%$ Rice flour & $5.85 \pm 0.79^{a}$ & $6.38 \pm 0.66^{\mathrm{a}}$ & $7.14 \pm 0.79^{a}$ & $6.81 \pm 0.61^{a}$ & $7.19 \pm 0.41^{a}$ \\
\hline $100 \%$ Rice flour $+10 \%$ BP & $6.47 \pm 0.92^{b}$ & $5.91 \pm 0.76^{b}$ & $6.28 \pm 0.56^{b}$ & $6.57 \pm 0.51^{a}$ & $7.61 \pm 0.81^{a}$ \\
\hline $50 \%$ Rice flour $+50 \%$ Quinoa flour & $6.38 \pm 0.49^{b}$ & $6.52 \pm 0.61^{a}$ & $6.23 \pm 0.53^{b}$ & $6.14 \pm 0.72^{a}$ & $6.19 \pm 0.81^{b}$ \\
\hline $50 \%$ Rice flour $+50 \%$ Quinoa flour $+10 \%$ BP & $6.52 \pm 0.61^{b}$ & $5.85 \pm 0.72^{b}$ & $6.19 \pm 0.87^{b}$ & $6.52 \pm 0.61^{a}$ & $7.23 \pm 0.94^{\mathrm{a}}$ \\
\hline $100 \%$ Quinoa flour & $6.47 \pm 0.63^{b}$ & $6.47 \pm 0.81^{\mathrm{a}}$ & $5.85 \pm 0.85^{b}$ & $6.14 \pm 0.79^{a}$ & $7.38 \pm 0.81^{\mathrm{a}}$ \\
\hline $100 \%$ Quinoa flour+ $10 \% \mathrm{BP}$ & $6.76 \pm 0.83^{b}$ & $5.52 \pm 0.51^{b}$ & $5.23 \pm 0.62^{c}$ & $6.23 \pm 1.17^{a}$ & $7.95 \pm 0.86^{\mathrm{a}}$ \\
\hline
\end{tabular}

Results are expressed as Mean \pm Standard deviation.. Values with different superscripts $(a, b, c)$ in a column differ significantly $(p<0.05)$.

Table 6b: Sensory characteristics of unfortified and freeze-dried blueberry powder fortified cookies

decrease springiness. Tables $5 \mathrm{~b}$ represent the texture properties of fortified and unfortified cookies. Quinoa flour and blueberry powder fortification were found to increase the hardness in cookies. No significant effect of flour or fortification was seen on fracturability of cookies.

\section{Sensory evaluation}

Hedonic ratings for product attributes and overall likeability for unfortified and fortified muffins and cookies are presented in Table $6 \mathrm{a}$ and $6 \mathrm{~b}$. A Hedonic score of 5 was considered neutral, above 5 was considered to be in the desirable range, and a score below 3 was unacceptable.

Muffins are sweet, high-Calorie baked products, appreciated by consumers for their pleasant taste and soft texture. The Maillard reaction that occurs during baking produces slightly darker muffin crusts compared to its crumb [25]. As seen with textural measurements, both Quinoa flour and blueberry powder fortification increased hardness. Harder texture of fortified 100\% Quinoa flour muffins showed lowest (5.14) hedonic rating for Texture. The lowest score of overall acceptance (5.28) was also associated with its hard texture. Quinoa flour also has a natural bitter taste; which led to a lower value for sweetness (5.13 for $100 \%$ Quinoa flour and 4.25 for the blueberry fortified 100\% Quinoa flour muffins), which also reduced the overall acceptability from 6.23 to 5.28. The values were still in the neither like nor dislike range. Both unfortified and fortified 100\% Rice flour muffins show highest scores for flavor, texture, sweetness and overall acceptance.

Blueberry fortification reduced the hardness of all three flour formulated cookies. The Hedonic rating for overall acceptance was highest (7.95), for the blueberry fortified 100\% Quinoa flour cookies. Sweetness score was highest (7.14), for unfortified 100\% Rice flour cookies. The freeze dried blueberry powder also has a pleasant flavor, and Blueberry fortified 100\% Quinoa flour cookies had the highest flavor score (6.76).

Blueberry powder fortification was found to improve the flavor and overall acceptability. Although, blueberry powder itself does not have any specific flavor, but its polyphenolic composition inhibits Maillard reaction during baking to produce a different flavor acceptable to the consumer [26]. Maillard reaction products have also been shown to possess antioxidant activity in food products in which they are formed [27]. Blueberry powder fortified $100 \%$ Rice flour muffin was observed 
Citation: Bhaduri S, Navder KP (2014) Freeze Dried Blueberry Powder Fortification Improves the Quality of Gluten Free Snacks. J Food Process Technol 5: 396. doi:10.4172/2157-7110.1000396

to have higher overall acceptance than unfortified $100 \%$ Rice flour muffin.

In summary, the best overall acceptable muffin was the $10 \%$ freezedried blueberry powder fortified $100 \%$ Rice muffin, while the most acceptable cookie was the one made with $100 \%$ Quinoa flour fortified with $10 \%$ freeze-dried powder.

\section{Conclusions}

Despite its slightly bitter taste, Quinoa flour produces acceptable gluten free baked products that are high in fiber and rich in antioxidants. In addition, dried blueberry powder is a simple way to improve the shelf life and increase phytochemical and antioxidant content in diet.

\section{Acknowledgments}

The work was supported by PSC-CUNY-TRADA-43-29 grant.

\section{References}

1. Hischenhuber C, Crevel R, Jarry B, Mäki M, Moneret-Vautrin DA, et al. (2006) Review article: safe amounts of gluten for patients with wheat allergy or coeliac disease. Aliment Pharmacol Ther 23: 559-575.

2. Repo-Carrasco VRK, Hellström J, Pihlava JM, Pirjo HM (2010) Flavonoids and other phenolic compounds in Andean indigenous grains: Quinoa (Chenopodium quinoa), kañiwa (Chenopodiumpallidicaule) and kiwicha (Amaranthuscaudatus). Food Chem 120: 128-133.

3. González Martín MI, Wells Moncada G, Fischer S, Escuredo O (2014) Chemical characteristics and mineral composition of quinoa by near-infrared spectroscopy. J Sci Food Agric 94: 876-881.

4. Vega-Gálvez A, Miranda M, Vergara J, Uribe E, Puente L, et al. (2010) Nutrition facts and functional potential of quinoa (Chenopodium quinoa willd.), an ancient Andean grain: a review. J Sci Food Agric 90: 2541-2547.

5. Laus MN, Gagliardi A, Soccio M, Flagella Z, Pastore D (2012) Antioxidant activity of free and bound compounds in quinoa (Chenopodium quinoa Willd.) seeds in comparison with durum wheat and emmer. J Food Sci 77: C1150-1155.

6. Palafox CH, Ayala-Zavala JF, González-Aguilar GA (2011) The role of dietary fiber in the bioaccessibility and bioavailability of fruit and vegetable antioxidants. J Food Sci 76: R6-6R15.

7. Denny A, Buttriss $\mathrm{J}$ (2007) Plant foods and health: focus on plant bioactives Funded under the EU 6th Framework Food Quality and Safety Thematic Priority. Contract FOOD-CT-2005-513944: European Food Information Resource (EuroFIR) Consortium.

8. Gonzalez AGA, Rodriguez VAZJF, Yhia EM (2010) Improvement of the antioxidant status of tropical fruits as a secondary response to some postharvest treatments. Trend Food Sci Technol 21: 475-482.

9. Boyer J, Liu RH (2004) Apple phytochemicals and their health benefits. Nutr J 3: 5 .

10. Apak R, Güçlü K, Demirata B, Ozyürek M, Celik SE, et al. (2007) Comparative evaluation of various total antioxidant capacity assays applied to phenolic compounds with the CUPRAC assay. Molecules 12: 1496-1547.

11. Pearson DA, Tan CH, German JB, Davis PA, Gershwin ME (1999) Apple juice inhibits human low density lipoprotein oxidation. Life Sci 64: 1913-1920.

12. Aprikian O, Duclos V, Guyot S, Besson C, Manach C, et al. (2003) Apple pectin and a polyphenol-rich apple concentrate are more effective together than separately on cecal fermentations and plasma lipids in rats. J Nutr 133: 1860-1865.

13. Coates EM, Popa G, Gill Cl, McCann MJ, McDougall GJ, et al. (2007) Colonavailable raspberry polyphenols exhibit anti-cancer effects on in vitro models of colon cancer. J Carcinog 6: 4

14. Bhaduri S (2013) A Comprehensive study on physical properties of two Glutenfree flour fortified muffins. J Food Process Technol 4: 251.

15. de la Barca AM, Rojas-Martínez ME, Islas-Rubio AR, Cabrera-Chávez $F$ (2010) Gluten-free breads and cookies of raw and popped amaranth flours with attractive technological and nutritional qualities. Plant Foods Hum Nutr 65: 241-246.

16. Larry Ma, James TP (1998) Aerobic Plate Count. Bacteriological Analytica Manual. (8 Edition). Revision A FDA USA 3: 1-13.

17. Rosales-Soto MU, Powers JR, Alldredge JR (2012) Effect of mixing time freeze-drying and baking on phenolics, anthocyanins and antioxidant capacity of raspberry juice during processing of muffins. J Sci Food Agric 92: 1511-1518.

18. Thaiponga $\mathrm{K}$, Boonprakoba U, Crosbyb K, Cisneros-Zevallosc L, Byrnec DH (2006) Comparison of ABTS, DPPH, FRAP, and ORAC assays for estimating antioxidant activity from guava fruit extracts. J Food Composition and Analysis 19: $669-675$

19. Chaovanalikit A, Wrolstad R (2004) Total anthocyanins and total phenolics of fresh and processed cherries and their antioxidant properties. J Food Sci 69 FCT67-FCT72.

20. Wende L, Mark DP, Trust B (2007) Effect of thermal processing on antioxidant properties of purple wheat bran. Food Chem 104: 1080-1090.

21. Abugoch JLE (2009) Quinoa (Chenopodium quinoa Willd.): composition, chemistry, nutritional, and functional properties. Adv Food Nutr Res 58: 1-31.

22. Acosta K, Cavender G, Kerr W (2011) Sensory and physical properties of muffins made with waxy whole wheat flour. J Food Quality 34: 343-351.

23. Del Rio D, Borges G, Crozier A (2010) Berry flavonoids and phenolics: bioavailability and evidence of protective effects. $\mathrm{Br} \mathrm{J}$ Nutr 104 Suppl 3 : S67-S90.

24. Chlopicka J, Pasko P, Gorinstein SPZ (2012) Total phenolic and total flavonoid content, antioxidant activity and sensory evaluation of pseudocereal breads. Food Sci and Technol 46: 548-555

25. Martínez CS, Sanz T, Salvador AM FS (2012) Rheological, textural and sensorial properties of low-sucrose muffins reformulated with sucralose/ polydextrose. LWT. Food Sci and Technol 45: 213-220.

26. Lin L, Liu H, Yu Y, Lin S, Mau J (2009) Quality and antioxidant property of buckwheat enhanced wheat bread. Food Chem 112: 987-991.

27. Vhangani LN, Van Wyk J (2013) Antioxidant activity of Maillard Reaction Products (MRPs) derived from fructose-lysine and ribose-lysine model systems. Food Chem 137: 92-98. 